\title{
Metabolic Bone Disease of Prematurity: A Review of Minerals Supplementation and Disease Monitoring
}

Valeria Anna Manfredini ${ }^{1 *}$, Chiara Cerini ${ }^{2}$, Chiara Giovanettoni ${ }^{1}$, Emanuela Alice Brazzoduro ${ }^{1}$ and Rossano Massimo Rezzonico ${ }^{1}$

1Neonatal intensive care Unit, "G. Salvini” Hospital, RHO, Milan, Italy

2Division of Infectious Diseases, Department of Pediatrics, Children's Hospital Los Angeles, USA

*Corresponding author: Valeria Anna Manfredini, MD, Corso Europa 250, 20017, RHO (Milano), Italy, Tel: +39-02-994303261; Fax +39-02-994303019; E-mail: valeria.manfredini@yahoo.it

Rec date: July 13, 2015; Acc date: August 5, 2015; Pub date: August 10, 2015

Copyright: @ 2015Manfredini VA. This is an open-access article distributed under the terms of the Creative Commons Attribution License, which permits unrestricted use, distribution, and reproduction in any medium, provided the original author and source are credited.

\begin{abstract}
Metabolic bone disease is a frequent condition in very low birth weight (VLBW) infants. In order to prevent the disease, the provision of high amount of calcium and phosphate in parenteral nutrition solutions and during transition to the full enteral feedings is crucial. Current practice supports early aggressive mineral supplementation. In this review, we will discuss data from the recent literature regarding the recommendation for supplementation of calcium, phosphate and vitamin D in VLBW infants and the interpretation of indirect markers of bone metabolism for screening, diagnosis and monitoring high risk infants, as well as to guide treatment.
\end{abstract}

Keywords: Preterm infants; Calcium; Phosphorus; Osteopenia; Bone mineralization

\section{Introduction}

Metabolic bone disease of the prematurity (MBDP), also known as preterm newborn osteopenia or neonatal rickets, is a leading cause of pathological fractures in very low birth weight infants (VLBW, birth weight $<1500 \mathrm{~g}$ ), and in the long-term has been implicated with poor growth during childhood. It is characterised by a reduction of bone mineral density resulting from either increased bone reabsorption or decreased bone mineralisation [1]

MBDP affects up to $23 \%$ of VLBW newborns [1], and up to $55 \%$ of those extremely low birth weight (ELBW, birth weight $<1000 \mathrm{~g}$ ) [2]. MBDP mainly occurs between ten and sixteen weeks postnatally and may be under-recognized until demineralisation is severely established. Factors contributing to the development of MBDP include preterm birth given the reduced transplacental mineral release to the fetus, and chronic conditions related to prematurity, such as bronchopulmonary dysplasia (BPD) and necrotizing enterocolitis, because of reduced nutritional and mineral intake associated to these conditions. Indeed, providing adequate supply of calcium and phosphate in preterm infants has always been a challenge for neonatologists, because of feed intolerance and inadequate mineral content in human or formula milk. Further restrictions are due to the solubility of calcium and phosphorus in parenteral nutrition (PN) solutions limiting the amount of minerals that can be supplemented, along with the side effects of prolonged fluid restrictions, diuretics, high dose systemic steroids, and immobilisation [3].

Diagnosis of MBDP is established upon radiographic evidence of reduced bone mineral density. While no biochemical tests are diagnostic, a number of easily accessible serum and urinary markers of bone metabolism have been used for early detection and monitoring of osteopenia: serum calcium $\left(\mathrm{Ca}_{\mathrm{s}}\right)$, phosphate $\left(\mathrm{P}_{\mathrm{s}}\right)$, and alkaline phosphatase (ALP), urinary calcium $\left(\mathrm{Ca}_{\mathrm{u}}\right)$, phosphate $\left(\mathrm{P}_{\mathrm{u}}\right)$ and creatinine $\left(\mathrm{Cr}_{\mathrm{u}}\right)$. Their measurements are used to state the renal tubular reabsorption of phosphate $\left(\mathrm{TRP}=1-\left(\mathrm{P}_{\mathrm{u}} / \mathrm{P}_{\mathrm{sp}}{ }^{\star} \mathrm{Cr}_{\mathrm{s}} / \mathrm{Cr}_{\mathrm{u}}\right)^{\star} 100\right)$ and the $\mathrm{Ca}_{\mathrm{u} /} \mathrm{Cr}_{\mathrm{u}}$ ratio (Table 1). Early nutritional intervention is essential in order to promote bone deposition and avoid bone demineralisation. Adequate amounts of calcium and phosphate must be provided with $\mathrm{PN}$, increased during transition to the exclusive enteral feeding, and maybe continued when the infant is on full feeds.

\section{Calcium and Phosphorus Homeostasis and Intake}

Calcium and phosphate are the major inorganic bone constituents. In utero, greater skeletal development occurs during the third trimester; between 24 and 37 weeks of gestation the $80 \%$ of the mineral accretion is achieved [4]. During these weeks, $310 \mathrm{mg}$ of calcium and $170 \mathrm{mg}$ of phosphorus are required to allow normal fetal weight gain, of approximately $30 \mathrm{~g}$ per day [5].

It has been suggested that placental insufficiency might increase the risk of neonatal rickets and account for early mineral deficiency, as a consequence of the reduced transfer of phosphorus to the fetus [6].

Compared to term infants, preterm babies are thus likely to require higher intake of calcium and phosphorus [7].

Despite modern PN solutions can theoretically match in utero accretion rates, the solubility of calcium and phosphorus in $\mathrm{PN}$ might be limited by temperature, amino acids, glucose and lipid concentrations as well as by the $\mathrm{pH}$ of the solution.

Current practice recommendations [8], state that at least 12.5 $\mathrm{mmol} / \mathrm{L}(50 \mathrm{mg} / \mathrm{dl})$ up to $15 \mathrm{mmol} / \mathrm{L}(60 \mathrm{mg} / \mathrm{dL})$ of calcium and 13 $\mathrm{mmol}(40 \mathrm{mg} / \mathrm{dL})$ up to $15 \mathrm{mmol} / \mathrm{L}(46 \mathrm{mg} / \mathrm{dL})$ of phosphorus should be administered by parenteral route. When the fluid intake reaches 150 $\mathrm{mL} / \mathrm{Kg} /$ day, this would give a supply of $75-90 \mathrm{mg} / \mathrm{Kg} /$ day of calcium and of $60-70 \mathrm{mg} / \mathrm{Kg} /$ day of phosphorus. Such amounts have shown to provide the proper ratio (1:5 to 1.7:1) of calcium and phosphate in order to guarantee bone deposition and to prevent early neonatal hypocalcemia. However, given the sub-optimal mineral retention rates, only the equivalent to $70 \%$ of the intrauterine mineralization would be achieved [9]. 
Currently recommended oral daily intake of calcium and phosphorus varies widely between international committees [10], from a minimum of 120 to a maximum of $220 \mathrm{mg} / \mathrm{Kg} /$ day of calcium and from 65 to $140 \mathrm{mg} / \mathrm{Kg} /$ day of phosphate. These amounts are higher than those suggested in the previews decades and have changed the current practice of mineral supplementation [3].

As a matter of fact, the introduction of a more aggressive supplementation and the routine use of breast milk fortifiers or preterm high mineral containing formulas has led to a dramatic reduction, by the $50 \%$ approximately, in the frequency of the MBDP, especially in ELBW newborns [11].

During weaning from $\mathrm{PN}$ phosphate intestinal absorption remains between $80 \%$ and $90 \%$, and recommended intake are intended to maintain the optimal calcium to phosphorus ratio suggested for preterm babies $[7,12]$. In contrast, calcium intestinal absorption is limited to $60 \%$ of the dietary intake and is influenced by vitamin D status, solubility of calcium salts and lipid intake. At this rate of assimilation, an infant receiving $120 \mathrm{Kcal} / \mathrm{Kg}$ /day would only absorb $25 \mathrm{mg} / \mathrm{Kg} /$ day of calcium from human unfortified milk $(67 \mathrm{Kcal} / \mathrm{dL})$ given its low calcium content $(25 \mathrm{mg} / \mathrm{dL})$.

Providing fortification $(80 \mathrm{Kcal} / \mathrm{dL})$, calcium concentration rises to $145 \mathrm{mg} / \mathrm{dL}$ accounting for a total amount of calcium of $220 \mathrm{mg} / \mathrm{Kg} /$ day that should allow for absorption of $120-130 \mathrm{mg} / \mathrm{Kg} /$ day [7] and suit the calcium intake recommended for ELBW infants receiving exclusive enteral nutrition $[7,13]$.

When adequate amounts of calcium and phosphate are provided, the excessive aliquots of both minerals is excreted with urine and a $\mathrm{Ca}_{\mathrm{u}} / \mathrm{Cr}_{\mathrm{u}}$ ratio $<0.6$, along with a normal urinary phosphate excretion confirmed by a TRP between $80 \%$ and $90 \%$ is found. If sudden detrimental conditions arise, renal compensation rapidly leads to a complete reabsorption of phosphate from urine, thus increasing the TRP to pathologic values, greater than $90 \%$. Collaterally, despite low values of $\mathrm{Ca}_{\mathrm{s}}$ are potentially found, paradoxical hypercalciuria might be observed $\left(\mathrm{Ca}_{\mathrm{u}} / \mathrm{Cr}_{\mathrm{u}}>0,6\right)$, following the lack of phosphate leading to a reduced calcium deposition in the hydroxyapatite crystals of the bone.

Currently recommended mineral supplementations should allow to maintain normal serum and urinary levels but also mimic in utero bone accretion rates for calcium and phosphorus.

For infants with greater mineral requirement, suitable oral solutions are displayed in Table 2.

\section{Vitamin D Supplementation}

It has been suggested that during the first month of life calcium absorption is independent from vitamin D supplementation and occurs passively via a "nonsaturable", non-vitamin D dependent, presumably paracellular process [14]. However, in preterm infants the exact timing and proportion of vitamin D-dependent absorption of calcium and phosphorus is unknown. For preterm infants, a vitamin D intake of 800-1000 IU/day is recommended from the European Society for Paediatric Gastroenterology Hepatology and Nutrition (ESPGHAN) guidelines [15]. However, the American Academy of Pediatrics (AAP) has raised concerns about the potential risks related to such high concentration of vitamin D, especially for ELBW infants for whom the upper tolerable intake is unknown. A randomized controlled trial by Alizadeh et al. demonstrated that $400 \mathrm{IU} /$ day of vitamin $\mathrm{D}$ are equally effective as $1000 \mathrm{IU} /$ day in preventing osteopenia of prematurity [16]. More recently, the same authors have shown equal efficacy of a lower dose of $200 \mathrm{IU} /$ day in preventing biochemical, radiological and clinical presentation of rickets in preterm newborns [17].

Interestingly, Isojima et al. [18], found no statistically significant differences in the height standard deviation score (SDS) at 3 years of age in two groups of VLBW infants with MBDP who did or did not receive standard vitamin $\mathrm{D}$ supplementation since birth. Pending further research, for preterm infants the AAP recommendations to provide 200 to $400 \mathrm{IU} /$ day are accepted [19].

Preterm infants are able to hydroxylate the inactive, monohydroxylated vitamin $\mathrm{D}$ to its active, dehydroxylated form (calcitriol) since the 24th week of gestation [14]. Supplementing preterm newborns with active dehydroxylated vitamin $D$ is thus not warranted. However, calcitriol suppresses parathyroid hormone (PTH) secretion, minimizing phosphorus wasting while increasing intestinal calcium and phosphorus uptake. Hence, calcitriol administration $(0.05$ $\mathrm{mcg} / \mathrm{kg} /$ day up to $0.2 \mathrm{mcg} / \mathrm{Kg} /$ day) might be reasonable for those babies receiving exclusive total $\mathrm{PN}$ to prevent or treat secondary hyperparathyroidism [20].

\section{Biochemical Markers for MBDP Management}

Monitoring markers of bone metabolism is essential for the management of MBDP. Serum calcium alone is not a good marker since its level is maintained stable at the expense of the bone, as a consequence of PTH secretion. Instead, serum levels of phosphorus and alkaline phosphatase (ALP) are better indicators of disease.

In preterm infants, ALP levels may not peak until 6-12 weeks of age and lack correlation with severity of demineralization [21].

However, ALP levels greater than $500 \mathrm{U} / \mathrm{L}$ are suggestive of altered bone homeostasis. ALP levels higher than $900 \mathrm{U} / \mathrm{L}$, associated with serum phosphorus levels persistently lower than $1.8 \mathrm{mmol} / \mathrm{L}(5.5$ $\mathrm{mg} / \mathrm{dL}$ ) have diagnostic sensitivity and specificity of $70 \%$ and $100 \%$, respectively [22].

A major concern when managing VLBW patients with increased values of ALP remains the risk for reduced mineralisation and stunted linear growth.

Increasing data suggest an association between prematurity and reduced bone strength in childhood [23], however whether VLBW infants are at increased risk for reduced bone mineral content (BMC) in adulthood is still debated.

Quintala et al. found that preterm infants $(28.4<$ gestational age $<$ 32) with high ALP levels at birth and at 6 months had lower values of $\mathrm{BMC}$ than full term infants during early life, but reached normal values at 6 months of corrected age. Interestingly, the rapid recovery of BMC occurred regardless the type of milk the infants had received [24].

The association between MBDP and stunted growth in VLBW infants has also been investigated.

Isojima et al. documented a negative correlation between peak serum ALP activity levels in early life and height standard deviation score (SDS) at three years of age. Serum phosphorus level was also identified as an independent predicting factor for height SDS. A statistically significant difference of $\mathrm{P}_{\mathrm{s}}$ levels between infants with or without height catch-up growth was found in the analysis restricted to small for gestational age infants, known to be at higher risk for BMDP 
compared to VLBW babies with adequate weight for gestational age. This positive correlation between height SDS and serum phosphate levels at peak ALP thus suggests that MBDP, particularly hypophosphatemia, may affect the long-term height prognosis in VLBW infants.

Moreover, no correlation was found between $\mathrm{Ca}_{s}$ at peak serum ALP and height SDS at three years of age, thus confirming the role of hypophosphatemia in the aetiology and long term outcomes of the MBDP [18].

\section{Summary and Conclusion}

MBDP is frequent in VLBW infants and requires early nutritional intervention.

In order to prevent and treat the disease essential points need to be acknowledged:

1) Identify subjects at higher risk for MBDP:

- Newborns less than 32 weeks g.a. or $1500 \mathrm{~g}$ at birth.

- Newborns receiving PN for more than 4 weeks.

- Newborn receiving prolonged therapies with steroids or diuretics.
2) Provide early calcium (12.5 - $15 \mathrm{mmol} / \mathrm{L})$ and phosphate (13-15 $\mathrm{mmol} / \mathrm{L}$ ) supplementation in $\mathrm{PN}$ and oral vitamin $\mathrm{D}$ supplementation (200-400 IU/day).

3) Assess $\mathrm{Ca}_{s}, \mathrm{P}_{s}$, serum ALP, serum creatinine $\mathrm{Ca}_{\mathrm{u}} \mathrm{P}_{\mathrm{u}}$ and urinary creatinine at birth and closely monitor these biomarkers (i.e. every 2 weeks).

4) Assess and monitor $\mathrm{Ca}_{\mathrm{u}} / \mathrm{Cr}_{\mathrm{u}}$ and renal TRP $\left[\mathrm{TRP}=1-\left(\mathrm{P}_{\mathrm{u}} /\right.\right.$ $\left.\left.\mathrm{P}_{\mathrm{s}}{ }^{\star} \mathrm{Cr}_{\mathrm{s}} / \mathrm{Cr}_{\mathrm{u}}\right)^{\star} 100\right]$.

5) Provide the most appropriate supplementation in the setting of deranged bone metabolism.

-Adjust the amounts of calcium (12.5 -15 mmol/L) and phosphate $(13-15 \mathrm{mmol} / \mathrm{L})$ in $\mathrm{PN}$.

- Fortify the human milk and/or provide preterm enriched formula.

- Give additional oral supplementation (Table 2).

6) Measure vitamin D in the setting of persistently altered serum and urinary findings despite aggressive supplementation in provided.

7) Consider calcitriol supplementation $(0.05 \mathrm{mcg} / \mathrm{kg} /$ day up to 0.2 $\mathrm{mcg} / \mathrm{Kg} /$ day) for patients on total $\mathrm{PN}$ with secondary hyperparathyroidism $(\mathrm{PTH}>100 \mathrm{pg} / \mathrm{mL})$.

\begin{tabular}{|l|l|}
\hline Markers & Levels of Ostopenia \\
\hline Alcaline Phosphatase (IU/L) & $>500$ \\
\hline Urinary calcium ${ }^{*}$ Urinary creatinine* & $>0,6$ \\
\hline TRP§ $(\%)$ & $>95$ \\
\hline Plasma Phosphate $(\mathrm{mg} / \mathrm{dL})$ & $<5,5$ \\
\hline *spot urine & \\
\hline §renal tubular reabsorption=1- (Pu/Psp $\left.{ }^{*} \mathrm{Crp} / \mathrm{Cru}\right)^{*} 100$ & \\
\hline
\end{tabular}

Table 1: Main markers of bone metabolism in the preterm newborn with metabolic bone disease.

\begin{tabular}{|c|c|c|}
\hline Solution & Composition & Dosage and notes \\
\hline $\begin{array}{l}\text { Calcium carbonate/ calcium lactate } \\
\text { gluconate }\end{array}$ & $\begin{array}{l}1132 \mathrm{mg} \text { of calcium lactate gluconate plus } 875 \mathrm{mg} \\
\text { of calcium carbonate provide } 500 \mathrm{mg} \text { of ionised } \\
\text { calcium }\end{array}$ & $\begin{array}{l}50 \mathrm{mg} \text { of ionised calcium given every } 12 \text { or } 6 \text { hours } \\
\text { Administer at distance (at least } 2 \text { hours) from phosphate supplements }\end{array}$ \\
\hline $\begin{array}{l}\text { Sodium phosphate monobasic } \\
\text { dehydrate }\end{array}$ & $\begin{array}{l}7.8 \mathrm{~g} \text { diluted in } 50 \mathrm{~mL} \text { of pure water provide } 30 \mathrm{mg} \\
\text { of phospate per } \mathrm{mL}\end{array}$ & $\begin{array}{l}1 \mathrm{~mL} \text { of solution every } 12 \text { or } 6 \text { hours } \\
\text { Administer at distance (at least } 2 \text { hours) from calcium supplements }\end{array}$ \\
\hline
\end{tabular}

Table 2: Available oral solutions providing additional calcium and phosphate supplements.

\section{References}

1. Koo WW, Sherman R, Succop P, Krug-Wispe S, Tsang RC, et al. (1989) Fractures and rickets in very low birth weight infants: conservative management and outcome. J Pediatr Orthop 9: 326-330.

2. McIntosh N, DeCurtis M, Williams JR (1989) Failure of mineral supplementation to reduce incidence of rickets in very low birth weight infants: conservative management and outcome. J Pediatr 9: 326-329.

3. Bozzetti V, Tagliabue P (2009) Metabolic Bone Disease in preterm newborn: an update on nutritional issues. Ital J Pediatr 35: 20.
4. Greer FR, Tsang RG (1985) Calcium, phosphorus and vitamin D requirements for the preterm infants. In: Vitamin and minerals requirements in preterm infants. Tsang RC (ed). NY: Marcel Deer, 99-136.

5. Sparks JW (1984) Human intrauterine growth and nutrient accretion. SeminPerinatol 8: 74-93.

6. Holland PC, Wilkinson AR, Diez J, Lindsell DR (1990) Prenatal deficiency of phosphate, phosphate supplementation, and rickets in verylow-birthweight infants. Lancet 335: 697-701.

7. Abrams SA. Committee on Nutrition (2013) Calcium and vitamin d requirements of enterally fed preterm infants. Pediatrics 131: e1676-1683.

8. Pereira-da-Silva L, Costa A, Pereira L, Filipe A, Virella D, et al. (2011) Early high calcium and phosphorus intake by parenteral nutrition 
Citation: Manfredini VA, Cerini C, Giovanettoni C, Brazzoduro EA, Rezzonico RM (2015) Metabolic Bone Disease of Prematurity: A Review of Minerals Supplementation and Disease Monitoring. J Neonatal Biol 4: 187. doi:10.4172/2167-0897.1000187

Page 4 of 4

prevents short-term bone strength decline in preterm infants. J Pediatr Gastroenterol Nutr 52: 203-209.

9. Riefen RM, Zlotkin S (1993) Microminerals. In Nutritional Needs of the Preterm Infant, Williams and Wilkins, Baltimore, USA.

10. Abrams SA; Committee on Nutrition (2013) Calcium and vitamin d requirements of enterally fed preterm infants. Pediatrics 131: e1676-1683.

11. Lyon AJ, McIntosh N, Wheeler K, Williams JE (1987) Radiological rickets in extremely low birthweight infants. Pediatr Radiol 17: 56-58.

12. Rowe JC, Goetz CA, Carey DE, Horak E (1987) Achievement of in utero retention of calcium and phosphorus accompanied by high calcium excretion in very low birth weight infants fed a fortified formula. J Pediatr 110: 581-585.

13. Harrison CM, Johnson K, McKechnie E (2008) Osteopenia of prematurity: a national survey and review of practice. Acta Paediatr 97: 407-413.

14. Bronner F, Salle BL, Putet G, Rigo J, Senterre J (1992) Net calcium absorption in premature infants: results of 103 metabolic balance studies. Am J Clin Nutr 56: 1037-1044.

15. Agostoni C, Buonocore G, Carnielli VP, De Curtis M, Darmaun D, et al. (2010) Enteral nutrient supply for preterm infants: commentary from the European Society of Paediatric Gastroenterology, Hepatology and Nutrition Committee on Nutrition. J Pediatr Gastroenterol Nutr 50: 85-91.

16. Alizadeh P, Naderi F, Sotoudeh K (2006) A Randomized Clinical Trial: Prophylactic effects of vitamin D on different indices of ostopenia of prematurity. Iranian J Public Health 35: 58-63.
17. Alizadeh Taheri P, Sajjadian N, Beyrami B, Shariat M (2014) Prophylactic effect of low dose vitamin $\mathrm{D}$ in osteopenia of prematurity: a clinical trial study. Acta Med Iran 52: 671-674.

18. Isojima T, Kushima R, Goishi K, Tsuchida S, Watanabe T, et al. (2015) Mineral status of premature infants in early life and linear growth at age three. Pediatr Int.

19. Hany A, Abdel-Hady H (2015) Vitamin D and the neonate: An update. Journal of Clinical Neonatology 4: 1-7.

20. Chen HY, Chiu LC, Yek YL, Chen YL (2012) Detecting rickets in premature infants and treating them with calcitriol: experience from two cases. Kaohsiung J Med Sci 28: 452-456.

21. Moreira A, Swischuk L, Malloy M, Mudd D, Blanco C, et al. (2014) Parathyroid hormone as a marker for metabolic bone disease of prematurity. J Perinatol 34: 787-791.

22. Tinnion RJ, Embleton ND (2012) How to use... alkaline phosphatase in neonatology. Arch Dis Child Educ Pract Ed 97: 157-163.

23. Embleton N, Wood CL (2014) Growth, bone health, and later outcomes in infants born preterm. J Pediatr (Rio J) 90: 529-532.

24. Quintal VS, Diniz EM, CaparboVde F, Pereira RM (2014) Bone densitometry by dual-energy X-ray absorptiometry (DXA) in preterm newborns compared with full-term peers in the first six months of life. J Pediatr (Rio J) 90: 556-562. 